NOTA CIENTÍFICA

\title{
SUBSTRATOS E AUXINAS NO ENRAIZAMENTO DE ESTACAS CAULINARES DE ESPINHEIRA-SANTA
}

\author{
SUBSTRATES AND AUXINS ON ROOTING OF STEM CUTTINGS OF \\ "ESPINHEIRA-SANTA"
}

\author{
Daniela Macedo de LIMA ${ }^{1}$ \\ Carmem Luisa da SILVA ${ }^{2}$ \\ Marlice RITTER ${ }^{2}$ \\ Luiz Antonio BIASI ${ }^{3}$ \\ Flavio ZANETTE ${ }^{4}$ \\ Katia Christina ZUFFELLATO-RIBAS ${ }^{5}$
}

\begin{abstract}
RESUMO
A espinheira-santa (Maytenus ilicifolia) é uma planta medicinal cujas folhas são utilizadas no tratamento de úlceras gástricas, mas apesar de sua importância, são poucas as informações publicadas sobre a produção de mudas e técnicas de propagação vegetativa da espécie. Este trabalho teve por objetivo avaliar o enraizamento de estacas caulinares de espinheirasanta submetidas à aplicação de duas auxinas, em dois substratos. Estacas caulinares semilenhosas foram preparadas com uma folha e $1 \mathrm{~cm}$ de caule, e caulinares herbáceas com duas folhas e 6 a $8 \mathrm{~cm}$ de comprimento. Estacas semilenhosas foram tratadas com ácido naftaleno acético (ANA 0, 1500, $3000 \mathrm{mg} \mathrm{L}^{-1}$ ) e herbáceas com ácido indolbutírico (AIB 0, 250, 500 e 1000 $\mathrm{mg} \mathrm{L}^{-1}$ ), em solução, e plantadas em tubetes contendo vermiculita ou fibra de casca de coco, sendo mantidas em casa-devegetação. Para estacas semilenhosas observou-se maior porcentagem de enraizamento na testemunha $(12,50 \%$ e $6,25 \%)$, número médio de raízes por estaca de 1,48 e 1,04 e comprimento médio de raízes de 1,28 e 2,03 cm para a testemunha, em vermiculita e fibra de casca de coco, respectivamente. Para estacas herbáceas obteve-se $16,00 \%$ de enraizamento, 2,46 raízes por estaca e comprimento médio de raízes de $0,89 \mathrm{~cm}$ para a testemunha, em vermiculita. Não houve enraizamento em fibra de casca de coco. Verificou-se maiores porcentagens de sobrevivência e menores porcentagens de mortalidade em estacas semilenhosas, enquanto que em estacas herbáceas observou-se o inverso. Estacas caulinares semilenhosas e herbáceas de espinheira-santa não respondem à aplicação ANA e AIB.
\end{abstract}

Palavras-chave: Maytenus ilicifolia; estaquia; propagação vegetativa; reguladores vegetais.

\begin{abstract}
Espinheira-santa (Maytenus ilicifolia) is a medicinal plant whose leaves are used for gastric ulcers treatments. In spite of its commercial and medicinal significance, few works are published about nursery tree production and vegetative propagation techniques for this plant. This study was carried out to evaluate the rooting of semihardwwod and herbaceous stem cuttings of espinheira-santa by auxins application in two kinds of substrates. Semihardwood cuttings had a leaf and $1 \mathrm{~cm}$ of stem while herbaceous cuttings consisting of 6 to $8 \mathrm{~cm}$ of length and had two leaves. Semihardwood cuttings were treated with naphtalene acetic acid (NAA 0, 1500, $3000 \mathrm{mg} \mathrm{L}^{-1}$ ) and herbaceous cuttings were treated with indol butiric acid (IBA $0,250,500,1000 \mathrm{mg} \mathrm{L}^{-1}$ ) solution. Cuttings were planted in plastic tubes containing vermiculite or coir dust like substrate and maintained in a greenhouse condition. The higher rooting percentage of semihardwood cuttings was observed in control plants $(12,50 \%$ and $6,25 \%)$, with root number average per cutting of 1,48 and 1,04 and root length average of 1,28 and 2,03 $\mathrm{cm}$ in vermiculite and coir dust substrate, respectively. Herbaceous cuttings rooting percentage in control cuttings was $16,00 \%$, with root number average per cutting of 2,46 and root length average of $0,89 \mathrm{~cm}$ in vermiculite. Herbaceous cuttings from coir dust fiber did not present roots. The largest percentage of alive cuttings and lowest percentage of dead cuttings was verified for semihardwood cuttings while in herbaceous cuttings was observed the inverse. Both kind of stem cuttings of espinheira-santa do not response for the application of NAA and IBA.

Key-words: Maytenus ilicifolia; cutting; vegetative propagation; plant regulators.
\end{abstract}

'Bióloga, Doutoranda em Agronomia, Produção Vegetal, UFPR. Bolsista da CAPES.

${ }^{2}$ Discente do Curso de Agronomia, UFPR. Bolsista de Iniciação Científica TN/CNPq.

${ }^{3}$ Engenheiro Agrônomo, Dr., Prof. Associado, Departamento de Fitotecnia e Fitossanitarismo (DFF), Setor de Ciências Agrárias (SCA), Bolsista de Produtividade em Pesquisa do CNPq. UFPR, Caixa Postal 19061, CEP 81531-990, Curitiba-PR. E-mail: biasi@ufpr.br. Autor para correspondência.

${ }^{4}$ Engenheiro Agrônomo, Dr., Prof. Titular, DFF, SCA, Bolsista de Produtividade em Pesquisa do CNPq. UFPR.

${ }^{5}$ Bióloga, Dra., Profa. Associada, Departamento de Botânica, Setor de Ciências Biológicas, Centro Politécnico, UFPR. 


\section{INTRODUÇÃO}

A distribuição da família Celastraceae é predominantemente tropical e subtropical (SOUZA e LORENZI, 2005), na qual se destaca a espécie Maytenus ilicifolia Mart. ex Reiss, conhecida como espinheira-santa, encontrada na região sul do Brasil e nos países vizinhos, Paraguai, Uruguai e leste da Argentina, ocorrendo principalmente no sub-bosque da Floresta Ombrófila Mista (CARVALHO-OKANO e LEITÃO-FILHO, 2004).

A propagação de espinheira-santa pode ocorrer por via sexuada, por sementes, ou assexuadamente, por rebentos nascidos das raízes, alporquia e mergulhia (SILVA JÚNIOR e OSAIDA, 2006), estacas caulinares herbáceas (SILVA, 1999) e também por meio da micropropagação (PEREIRA, 1998).

As auxinas são os reguladores vegetais com maior efetividade na promoção do enraizamento, cujo principal efeito está ligado à sua ação sobre a iniciação dos primórdios radiciais. Quando a auxina é aplicada em segmentos do caule, o transporte polar causa um rápido acúmulo da substância na porção basal, e, após algum tempo, a auxina acumulada nesse local poderá causar a produção de uma dilatação ou calo, com muitas células, formando novos centros meristemáticos ou ativando meristemas existentes que induzem a formação de raízes (HARTMANN et al., 2002).

Dos fatores externos que influenciam na formação de raízes, o substrato utilizado para o enraizamento de estacas é de grande importância na propagação vegetativa, pois, ele é o meio onde as raízes se desenvolvem e deve ser permeável, poroso, bem drenado, livre de patógenos, pragas e propágulos de ervas daninhas e ter baixa densidade (KÄMPF, 2000; WENDLING et al., 2002), bem como disponibilidade e viabilidade econômica.

Pela importância comercial e medicinal da espécie, são poucos os trabalhos publicados sobre a produção de mudas por propagação vegetativa, estando, segundo RADOMSKI e SCHEFFER (2004), os estudos sobre a espinheira-santa restritos às áreas de fármacos, sendo, portanto, pouco relacionados aos aspectos ecológicos e de manejo.

O presente trabalho teve por objetivo estudar - enraizamento de estacas caulinares de espinheira-santa submetidas à aplicação de ácido naftaleno acético (ANA) e ácido indol butírico (AIB), em dois substratos.

\section{METODOLOGIA}

Os ramos utilizados nos dois experimentos foram obtidos de plantas matrizes de seis anos do plantio existente na Estação Experimental do Canguiri, UFPR, localizada em Pinhais-PR. A coleta foi realizada no período da manhã, no mesmo dia de confecção das estacas, e os ramos foram acondicionados em recipientes contendo água. Após a confecção, as estacas foram submetidas a tratamento fitossanitário com hipoclorito de sódio a
0,5\% por 10 min e enxaguadas em água corrente durante $5 \mathrm{~min}$.

Foram realizados dois experimentos com estacas caulinares de espinheira-santa. No primeiro, utilizou-se estacas caulinares semilenhosas, as quais foram confeccionadas a partir de ramos de um ano coletados no mês de julho de 2005, com aproximadamente $1 \mathrm{~cm}$ de caule, uma gema e uma folha inteira. As bases das estacas foram imersas em soluções aquosas com diferentes concentrações de ANA $(0,1500$ e 3000 $\mathrm{mg} \mathrm{L}^{-1}$ ), por 10 segundos. No segundo, coletaramse ramos herbáceos de plantas matrizes de espinheira-santa formados após a poda realizada em julho de 2005 e coletados em novembro do mesmo ano. As estacas foram confeccionadas com comprimento de 6 a $8 \mathrm{~cm}$, contendo um par de folhas, com corte em bisel na base e reto acima da última gema axilar. As bases das estacas foram imersas em soluções alcoólicas (50\%) com diferentes concentrações de AIB $(0,250,500$ e 1000 $\mathrm{mg} \mathrm{L}^{-1}$ ), por 10 segundos.

O plantio foi realizado em tubetes de polipropileno com capacidade de $53 \mathrm{~cm}^{3}$, contendo vermiculita de granulometria fina e fibra de casca de coco como substratos. As estacas foram mantidas em casa-de-vegetação sob nebulização intermitente com o seguinte intervalo: 15 segundos de rega a cada 15 min, das 8 às $17 \mathrm{~h} ; 15$ segundos de rega a cada hora, das 17 às 23 h e 15 segundos de rega a cada 3 h, das 23 às 8 h. Aos 105 dias, para estacas caulinares e aos 270 dias após o plantio, para estacas caulinares semilenhosas, foram avaliadas as variáveis: porcentagem de estacas enraizadas, vivas com calos, vivas (sem raízes e sem calos) e mortas, número e comprimento médio de raízes (das três maiores raízes formadas por estaca $(\mathrm{cm})$.

Para testar a homogeneidade das médias utilizou-se o teste de Bartlett e para a comparação de médias, os dados foram submetidos ao Teste de Tukey a $5 \%$ de probabilidade. $O$ delineamento estatístico utilizado para ambos os experimentos foi inteiramente casualizado, sendo para estacas semilenhosas 6 tratamentos e 4 repetições de 20 estacas por parcela, com arranjo fatorial de $3 \times 2 \mathrm{e}$ para estacas herbáceas foram 8 tratamentos e 4 repetições de 24 estacas por parcela, com arranjo fatorial de $4 \times 2$

\section{RESULTADOS E DISCUSSÃO}

A análise de variância para estaquia semilenhosa revelou que não houve interação significativa entre os fatores substrato e concentração de ANA para as variáveis porcentagem de estacas enraizadas, comprimento das três maiores raízes e número de raízes, porcentagem de estacas com calos e de estacas vivas, indicando a independência dos fatores testados.

Com relação ao tipo de substrato, a comparação de médias para a porcentagem de estacas enraizadas não apresentou diferença estatística entre os dois substratos testados (Tabela 
LIMA, D.M. et al. Substratos e auxinas no enraizamento de estacas...

1). A vermiculita apresenta boa aeração e drenagem, elevada porosidade, com equilíbrio entre macro e microporos e alta capacidade de retenção de água (KÄMPF, 2000; HARTMANN et al., 2002). Já a fibra de casca de coco (coxim) é um substrato de baixa densidade e excelente aeração e retenção de umidade (DOLE e WILKINS, 1999).

TABELA 1 - Porcentagem de estacas caulinares semilenhosas de espinheira-santa enraizadas, número e comprimento médio de raízes, porcentagem de estacas com calos, vivas e mortas em dois substratos. UFPR, Curitiba - PR, 2005.

\begin{tabular}{|c|c|c|c|c|}
\hline \multirow{3}{*}{ Substrato } & \multicolumn{4}{|c|}{ Concentrações de ANA $\left(\mathrm{mg} \mathrm{L}^{-1}\right)$} \\
\hline & \multicolumn{4}{|c|}{ ESTACAS ENRAIZADAS (\%) } \\
\hline & 0 & 1500 & 3000 & Médias \\
\hline VERM & 12,50 & 5,00 & 7,50 & $8,33 \mathrm{~A}$ \\
\hline FCC & 6,25 & 3,75 & 6,25 & $5,42 \mathrm{~A}$ \\
\hline Médias & $9,38 \mathrm{a}$ & $4,38 \mathrm{a}$ & $6,88 \mathrm{a}$ & \\
\hline \multirow[t]{2}{*}{ CV (\%) } & \multicolumn{4}{|c|}{77,14} \\
\hline & \multicolumn{4}{|c|}{ NÚMERO MÉDIO DE RAÍZES } \\
\hline VERM & 2,12 & 1,37 & 0,94 & $1,48 \mathrm{~A}$ \\
\hline FCC & 0,75 & 1,00 & 1,37 & $1,04 \mathrm{~A}$ \\
\hline Médias & $1,44 \mathrm{a}$ & $1,19 \mathrm{a}$ & $1,16 \mathrm{a}$ & \\
\hline \multirow[t]{2}{*}{ CV $(\%)$} & \multicolumn{4}{|c|}{73,64} \\
\hline & \multicolumn{4}{|c|}{ COMPRIMENTO MÉDIO DE RAIIZES (cm) } \\
\hline VERM & 2,10 & 1,18 & 0,56 & $1,28 \mathrm{~A}$ \\
\hline FCC & 0,91 & 3,62 & 1,57 & $2,03 \mathrm{~A}$ \\
\hline Médias & $1,50 \mathrm{a}$ & $2,40 \mathrm{a}$ & $1,06 \mathrm{a}$ & \\
\hline \multirow[t]{2}{*}{ CV (\%) } & \multicolumn{4}{|c|}{109,98} \\
\hline & \multicolumn{4}{|c|}{ ESTACAS COM CALOS (\%) } \\
\hline VERM & 31,25 & 28,75 & 35,00 & $31,67 \mathrm{~B}$ \\
\hline FCC & 53,75 & 56,25 & 41,25 & $50,42 \mathrm{~A}$ \\
\hline Médias & $42,50 \mathrm{a}$ & $42,50 \mathrm{a}$ & $38,13 \mathrm{a}$ & \\
\hline \multirow[t]{2}{*}{ CV $(\%)$} & \multicolumn{4}{|c|}{26,28} \\
\hline & \multicolumn{4}{|c|}{ ESTACAS VIVAS (\%) } \\
\hline VERM & 18,75 & 12,50 & 16,25 & $15,83 \mathrm{~A}$ \\
\hline FCC & 28,75 & 23,75 & 18,75 & $23,75 \mathrm{~A}$ \\
\hline Médias & $23,75 \mathrm{a}$ & $18,12 \mathrm{a}$ & $17,5 \mathrm{a}$ & \\
\hline \multirow[t]{2}{*}{ CV (\%) } & \multicolumn{4}{|c|}{35,10} \\
\hline & \multicolumn{4}{|c|}{ ESTACAS MORTAS (\%) } \\
\hline VERM & $37,50 \mathrm{Ab}$ & $53,75 \mathrm{Aa}$ & $41,25 \mathrm{Aab}$ & 44,17 \\
\hline FCC & $11,25 \mathrm{Bb}$ & $16,25 \mathrm{Bb}$ & $33,75 \mathrm{Aa}$ & 20,42 \\
\hline Médias & 24,38 & 35,00 & 37,50 & \\
\hline CV (\%) & \multicolumn{4}{|c|}{24,95} \\
\hline
\end{tabular}

Médias seguidas da mesma letra maiúscula na vertical, para substratos, e médias seguidas da mesma letra minúscula na horizontal, para concentrações, não diferem significativamente pelo teste de Tukey a $5 \%$ de probabilidade.

VERM = vermiculita; FCC = fibra de casca de coco.

As estacas caulinares semilenhosas de $M$. ilicifolia apresentaram um baixo índice de enraizamento para os dois substratos testados, variando de 4,38 a 9,38\%, embora não tenha sido verificada diferença estatisticamente significativa entre os tratamentos testados (Tabela 1).

$\mathrm{Na}$ comparação de médias para as variáveis número de raízes formadas e comprimento médio das raízes não foi detectada diferença estatística entre os substratos testados e entre as concentrações de ANA (Tabela 1).

Comparando-se as médias para porcentagem de estacas com calos (Tabela 1) verificou-se diferença entre os substratos testados, sendo a fibra de casca de coco estatisticamente superior a vermiculita. A presença de calos pode ser um indício de enraizamento futuro, caso as estacas permanecessem por mais tempo em casa-de- vegetação. Nas espécies consideradas de difícil enraizamento geralmente há formação de calos precedentes à formação de raízes (HAMANN, 1998). Entretanto, a formação das raízes adventícias e dos calos é independente e sua ocorrência simultânea é explicada pelo fato de ambos envolverem o processo de divisão celular, dependente de condições internas e ambientais similares (HARTMANN et al., 2002). Para a porcentagem de estacas vivas não enraizadas não houve diferença estatística significativa entre os substratos e as concentrações de ANA (Tabela 1).

Para a porcentagem de estacas mortas houve interação significativa entre os fatores (Tabela 1). A fibra de casca de coco apresentou menor mortalidade que a vermiculita na testemunha e na concentração de $1500 \mathrm{mg} \mathrm{L}^{-1}$. 
LIMA, D.M. et al. Substratos e auxinas no enraizamento de estacas...

Para a estaquia herbácea os resultados obtidos pelo teste de Bartlett revelaram que as variâncias das variáveis porcentagem de estacas enraizadas, número de raízes e comprimento médio das três maiores raízes não foram homogêneas.
Mesmo após a transformação dos dados destas variáveis não foi verificada homogeneidade das variâncias. As médias para estas variáveis são apresentadas na Tabela 2, juntamente com a porcentagem de estacas com calo.

TABELA 2 - Porcentagem de estacas caulinares herbáceas de espinheira-santa enraizadas, número e comprimento médio de raízes, porcentagem de estacas com calos, vivas e mortas em dois substratos. UFPR, Curitiba - PR, 2005.

\begin{tabular}{|c|c|c|c|c|c|}
\hline \multirow{2}{*}{ Substrato } & \multicolumn{5}{|c|}{ Concentrações de AIB (mg L $\left.{ }^{-1}\right)$} \\
\hline & 0 & 250 & 500 & 1000 & Médias \\
\hline VERM & 16,00 & 6,50 & 5,30 & 4,00 & 7,95 \\
\hline FCC & 0,00 & 0,00 & 0,00 & 0,00 & 0,00 \\
\hline Médias & 8,00 & 3,25 & 2,65 & 2,00 & \\
\hline \multirow[t]{2}{*}{ CV (\%) } & \multicolumn{5}{|c|}{14,32} \\
\hline & \multicolumn{5}{|c|}{ NÚMERO MÉDIO DE RAÍZES } \\
\hline VERM & 2,46 & 1,42 & 1,54 & 3,00 & 2,11 \\
\hline FCC & 0,00 & 0,00 & 0,00 & 0,00 & 0,00 \\
\hline Médias & 1,23 & 0,71 & 0,77 & 1,50 & \\
\hline \multirow[t]{2}{*}{ CV (\%) } & \multicolumn{5}{|c|}{72,42} \\
\hline & \multicolumn{5}{|c|}{ COMPRIMENTO MÉDIO DE RAIIZES (cm) } \\
\hline VERM & 0,89 & 0,43 & 0,41 & 0,64 & 0,58 \\
\hline FCC & 0,00 & 0,00 & 0,00 & 0,00 & 0,00 \\
\hline Médias & 0,45 & 0,22 & 0,21 & 0,32 & \\
\hline \multirow[t]{2}{*}{$\mathrm{CV}(\%)$} & \multicolumn{5}{|c|}{92,16} \\
\hline & \multicolumn{5}{|c|}{ ESTACAS COM CALOS (\%) } \\
\hline VERM & 0,00 & 3,00 & 4,20 & 4,20 & 2,85 \\
\hline FCC & 2,00 & 3,00 & 0,00 & 1,00 & 1,50 \\
\hline Médias & 1,00 & 3,00 & 2,10 & 2,60 & \\
\hline \multirow[t]{2}{*}{ CV (\%) } & \multicolumn{5}{|c|}{28,76} \\
\hline & \multicolumn{5}{|c|}{ ESTACAS VIVAS (\%) } \\
\hline VERM & $14,75 \mathrm{Bc}$ & $27,25 \mathrm{Ab}$ & $31,50 \mathrm{Aa}$ & $25,50 \mathrm{Ab}$ & 24,80 \\
\hline FCC & $19,75 \mathrm{Ab}$ & $24,25 \mathrm{Aa}$ & $19,75 \mathrm{Bb}$ & $15,75 \mathrm{Bc}$ & 19.90 \\
\hline Médias & 17,30 & 25,70 & 25,60 & 20,60 & \\
\hline \multirow[t]{2}{*}{ CV (\%) } & \multicolumn{5}{|c|}{5,68} \\
\hline & \multicolumn{5}{|c|}{ ESTACAS MORTAS (\%) } \\
\hline VERM & $69,75 \mathrm{Ba}$ & $67,00 \mathrm{Bab}$ & $63,75 \mathrm{Bb}$ & $70,00 \mathrm{Ba}$ & 67,60 \\
\hline FCC & $78,50 \mathrm{Ab}$ & $73,25 \mathrm{Ac}$ & $80,25 \mathrm{Aab}$ & $83,00 \mathrm{Aa}$ & 78,80 \\
\hline Médias & 74,10 & 70,10 & 72,00 & 76,50 & \\
\hline CV (\%) & \multicolumn{5}{|c|}{2,56} \\
\hline
\end{tabular}

Médias seguidas da mesma letra maiúscula na vertical, para substratos, e médias seguidas da mesma letra minúscula na horizontal, para concentrações, não diferem significativamente pelo teste de Tukey a $5 \%$ de probabilidade.

VERM = vermiculita; FCC = fibra de casca de coco

Para as variáveis porcentagem de estacas vivas e de estacas mortas (Tabela 2) a análise de variância revelou que houve interação significativa entre os fatores substrato e concentração de AIB.

A comparação de médias indicou que no substrato vermiculita a porcentagem de estacas vivas $(31,50 \%)$ obtida no tratamento $500 \mathrm{mg} \mathrm{L}^{-1} \mathrm{AIB}$ (Tabela 2), foi estatisticamente superior às demais estudadas. Já para o substrato fibra de casca de coco, o tratamento $250 \mathrm{mg} \mathrm{L}^{-1}$ AIB, foi estatisticamente superior $(24,25 \%)$ aos demais para a taxa de sobrevivência das estacas. Em experimento realizado com diferentes tipos de miniestacas de cedro-rosa (caulinar, caulinar apical, caulinar intermediária, caulinar apical desfolhada e foliar), XAVIER et al. (2003) verificaram índices de enraizamento de $100,0 \%$ aos 37 dias bem como índices de sobrevivência de $96,80 \%$ aos 60 dias e de 84,60 aos 90 dias para as estacas caulinares.

Para a porcentagem de estacas mortas (Tabela 2), a comparação das médias revelou que a taxa de mortalidade no substrato vermiculita foi observada nos tratamentos 0 e $1000 \mathrm{mg} \mathrm{L}^{-1}$ AIB $(69,75 \%$ e $70,00 \%$, respectivamente), os quais não diferem entre si e são estatisticamente superiores aos demais. No caso do substrato fibra de casca de coco, a taxa de mortalidade estatisticamente superior (83\%) foi verificada no tratamento $1000 \mathrm{mg} \mathrm{L}^{-1} \mathrm{AIB}$.

No presente trabalho, em ambos os substratos, verificou-se altas taxas de mortalidade das estacas herbáceas de espinheira-santa, sendo a fibra de casca de coco numericamente superior a 
vermiculita. Talvez devido à alta capacidade de retenção de água, que pode ter provocado redução nos níveis de oxigênio na base das estacas. Resultados estes divergentes daqueles obtidos por BITENCOURT (2006) em experimento com estacas caulinares de Ginkgo biloba, no qual as menores porcentagens de mortalidade $(2,50$ a $13,75 \%)$ foram obtidas no substrato fibra de casca de coco.

Possivelmente a presença de uma menor quantidade de reservas nutritivas e co-fatores de enraizamento nas estacas herbáceas, quando comparadas as semilenhosas, ocasionou maiores índices de mortalidade.

\section{CONCLUSÕES}

1) A espinheira-santa é uma espécie de difícil enraizamento.

2) Estacas caulinares semilenhosas e herbáceas de espinheira-santa não respondem à aplicação das auxinas, ANA e AIB, respectivamente.

\section{REFERÊNCIAS}

1. BITENCOURT, J. de. Propagação de Ginkgo biloba L. (Ginkgoaceae). Curitiba, 2006. 83 f. Dissertação (Mestrado em Ciências Biológicas) - Curso de Pós-Graduação em Botânica, Setor de Ciências Biológicas, Universidade Federal do Paraná.

2. CARVALHO-OKANO , R.M.; LEITÃO-FILHO, H. de F.O gênero Maytenus Mol. emend. Mol. (Celastraceae) no Brasil extra-amazônico. In: REIS, M. S. dos; SILVA, S. R. (Org.) Conservação e uso sustentável de plantas medicinais e aromáticas: Maytenus spp., espinheira-santa. Brasília: AIBma, 2004. p. 11-52. v. 1. Coleção plantas medicinais e aromáticas, espinheira-santa.

3. DOLE, J.M.; WILKINS, H.F. Floriculture: principle and species. 1. ed. New Jersey: Prentice-Hall, 1999. 613 p.

4. HAMANN, A. Adventitious root formation in cuttings of loblolly pine (Pinus taeda L.): developmental sequence and effects of maturation. Trees, v. 12, p. 175-180, 1998.

5. HARTMANN, H.T.; KESTER, D.E.; DAVIES JR, R.T.; GENEVE, R.L. Plant propagation: principles e practices. 7. ed. New Jersey: Prentice Hall, 2002. 880 p.

6. KÄMPF, A.N. Substrato. IN: KÄMPF, A.N. Produção comercial de plantas ornamentais. Guaíba: Agropecuária, 2000. p. 45-73

7. PEREIRA, A.M.S. Micropropagação de Maytenus aquifolium Mart. e Maytenus ilicifolia Mart. (espinheira-santa). In: MING., L.C. (Coord.); SCHEFFER, M.C.; CORRÊA JÚNIOR, C.; BARROS, I.B.I.; MATTOS, J.K.A. Plantas medicinais, aromáticas e condimentares: avanços na pesquisa agronômica. v. 2. Botucatu: UNESP, 1998. p. 19-32.

8. RADOMSKI, M.I.; SCHEFFER, M.C. Características fenotípicas de 44 progênies de Maytenus ilicifolia Mart. Cultivadas no município de Ponta Grossa, PR. Colombo: EMBRAPA-CNPF, 2004. 6. p. (EMBRAPA-CNPF. Circular Técnica, 86).

9. SILVA, C. de P. Efeitos do ANA, ácido bórico, paclobutrazol e da época de coleta, no enraizamento de estacas caulinares de espinheira-santa (Maytenus aquifolia Mart.). Botucatu, 1999. $99 \mathrm{f}$. Tese (Doutorado em Ciências Biológicas, Botânica) - Instituto de Biociências, Universidade Estadual Paulista Julio de Mesquita Filho.

10. SILVA JÚNIOR, A.A.; OSAIDA, C.C. Espinheira-santa (Maytenus ilicifolia) - da flora ao medicamento. Agropecuária Catarinense, v. 19, n. 3, p. 36-40, 2006.

11. SOUZA, V.C.; LORENZI, H. Botânica sistemática: um guia ilustrado para identificação das famílias de Angiospermas da flora brasileira, baseado em APG II. Nova Odessa: Instituto Plantarum, 2005. 640 p.

12. WENDLING, I.; GATTO, A.; PAIVA, H.N.; GONÇALVES, W. Substratos, adubação e irrigação na produção de mudas. 1. ed. Viçosa: Aprenda Fácil Editora, 2002. 165 p. (Coleção Jardinagem e Paisagismo. Série Produção de Mudas Ornamentais).

13. XAVIER, A.; SANTOS, G.A. dos; OLIVEIRA, M.L. de. Enraizamento de miniestaca caulinar e foliar na propagação vegetativa de cedro-rosa (Cedrela fissillis Vel). Revista Árvore, v. 27, n. 3, p. 351-356, 2003.

Recebido em 04/04/2007 Aceito em 13/12/2007 

